$2012-2$

\title{
Characterising Domestic Electricity Consumption Patterns by Dwelling and Occupant Socio-economic Variables: an Irish Case Study
}

Fintan McLoughlin

Technological University Dublin

Aidan Duffy

Technological University Dublin, aidan.duffy@tudublin.ie

Michael Conlon

Technological University Dublin, michael.conlon@tudublin.ie

Follow this and additional works at: https://arrow.tudublin.ie/dubenart

Part of the Electrical and Electronics Commons

\section{Recommended Citation}

McLoughlin, F., Duffy, A. \& Conlon, M. (2012). Characterising domestic electricity consumption patterns by dwelling and occupant socio-economic variables: an Irish case study. Energy and Buildings, vol. 48, May, pp.240-248. doi:10.1016/j.enbuild.2012.01.037

This Article is brought to you for free and open access by the Dublin Energy Lab at ARROW@TU Dublin. It has been accepted for inclusion in Articles by an authorized administrator of ARROW@TU Dublin. For more information, please contact arrow.admin@tudublin.ie, aisling.coyne@tudublin.ie,gerard.connolly@tudublin.ie.

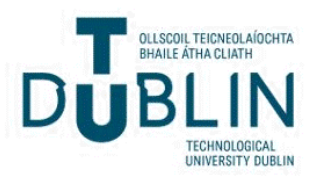




\section{AUTHOR QUERY FORM}

\begin{tabular}{|c|c|c|}
\hline 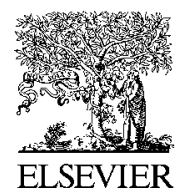 & Article Number: 3588 & $\begin{array}{l}\text { Please e-mail or fax your responses and any corrections to: } \\
\text { E-mail: corrections.esch@elsevier.thomsondigital.com } \\
\text { Fax: }+35361709272\end{array}$ \\
\hline
\end{tabular}

Dear Author,

Please check your proof carefully and mark all corrections at the appropriate place in the proof (e.g., by using on-screen annotation in the PDF file) or compile them in a separate list. Note: if you opt to annotate the file with software other than Adobe Reader then please also highlight the appropriate place in the PDF file. To ensure fast publication of your paper please return your corrections within 48 hours.

For correction or revision of any artwork, please consult http://www.elsevier.com/artworkinstructions.

Any queries or remarks that have arisen during the processing of your manuscript are listed below and highlighted by flags in the proof. Click on the ' $\underline{Q}$ ' link to go to the location in the proof.

\begin{tabular}{|l|c|}
\hline $\begin{array}{c}\text { Location in } \\
\text { article }\end{array}$ & $\begin{array}{c}\text { Query / Remark: click on the Q link to go } \\
\text { Please insert your reply or correction at the corresponding line in the proof }\end{array}$ \\
\hline$\underline{\text { Q1 }}$ & Please confirm that given names and surnames have been identified correctly. \\
& \\
\end{tabular}

Thank you for your assistance. 
Energy and Buildings xx (2012) xxx-xxx

Characterising domestic electricity consumption patterns by dwelling and occupant

Energy and Buildings $x x(2012) x x x-x x x$ socio-economic variables: An Irish case study

Fintan McLoughlin*, Aidan Duffy, Michael Conlon

- We examine the influence of dwelling and occupant characteristics on domestic electricity consumption. $>$ A multiple linear regression model was applied to four electrical parameters. Electricity consumption is strongly influenced by number of bedrooms and household composition. $\triangleright$ Time of use of electricity demand is strongly influenced by occupant characteristics. 


\title{
1 Characterising domestic electricity consumption patterns by dwelling and occupant socio-economic variables: An Irish case study
}

\author{
3. Q1 Fintan McLoughlin ${ }_{\wedge}^{\mathrm{a}, *}$, Aidan Duffy ${ }_{\wedge}^{\mathrm{a}},{ }_{\wedge}$ Michael Conlon ${ }_{\wedge}^{\mathrm{b}}$ \\ a School of Civil and Building Services and Dublin Energy Lab, Dublin Institute of Technology, Bolton St., Dublin 1, Ireland \\ ${ }^{\mathrm{b}}$ School of Electrical Engineering Systems and Dublin Energy Lab, Dublin Institute of Technology, Kevin St., Dublin 4, Ireland
}

\section{A R T I C L E I N F O}

\section{Article history:}

Received 22 August 2011

Received in revised form 19 January 2012

Accepted 30 January 2012

\section{Keywords:}

Domestic electricity consumption

pwelling and occupant characteristics

Electricity load profiles

\begin{abstract}
A B S T R A C T
This paper examines the influence of dwelling and occupant characteristics on domestic electricity consumption patterns by analysing data obtained from a smart metering survey of a representative cross section of approximately 4200 domestic Irish dwellings. A multiple linear regression model was applied to four parameters: total electricity consumption, maximum demand, load factor and time of use (ToU) of maximum electricity demand for a number of different dwelling and occupant socio-economic variables. In particular, dwelling type, number of bedrooms, head of household $(\mathrm{HoH})$ age, household composition, social class, water heating and cooking type all had a significant influence over total domestic electricity consumption. Maximum electricity demand was significantly influenced by household composition as well as water heating and cooking type. A strong relationship also existed between maximum demand and most household appliances but, in particular, tumble dryers, dishwashers and electric cookers had the greatest influence over this parameter. Time of use (ToU) for maximum electricity demand was found to be strongly influenced by occupant characteristics, $\mathrm{HoH}$ age and household composition. Younger head of households were more inclined to use electricity later in the evening than older occupants. The appliance that showed the greatest potential for shifting demand away from peak time use was the dishwasher.
\end{abstract}

(c) 2012 Published by Elsevier B.V.

\section{Introduction}

Throughout the EU, there has been a move towards smarter electricity networks, where increased control over electricity generation and consumption has been achieved with improvements in new technologies such as Advanced Metering Infrastructure (AMI). Residential smart metering is part of this and is seen as a necessary pre-requisite for the realisation of EU policy goals for increased renewable energy penetration, residential demand side management opportunities and improvements in energy efficiency, for achieving ambitious 20/20/20 targets.

EU-27 energy-related greenhouse gas emissions (GHG) targets for 2020 (based on a 2005 emissions baseline) include a reduction of $21 \%$ in greenhouse gas emissions for the emission trading sector across the EU-27 countries and a 10\% reduction for the non-trading sector across the EU. The $10 \%$ reduction across the EU-27 countries for the non-trading sector is broken up collectively for the different member states. Ireland has been assigned a target of $20 \%$ reduction in greenhouse gas emissions by 2020 [1]. Domestic electricity consumption is covered under the emissions trading sector scheme

\footnotetext{
* Corresponding author. Tel.: +353 14023918; fax: +353 14024035 .

E-mail address: fintan.mcloughlin@dit.ie (F. McLoughlin).
}

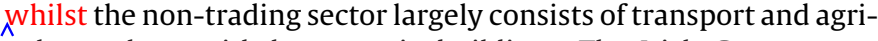
culture along with heat use in buildings. The Irish Government has committed to achieving a $20 \%$ reduction (compared to average energy use over the period $2001-2005$ ) in energy demand across the whole of the economy through energy efficiency measures by 2020 [2] and has also set a target of $40 \%$ electricity consumption from renewable sources by 2020 [3]. Other EU countries have committed to achieving similar targets to that outlined above.

Electricity consumption patterns for domestic dwellings are highly stochastic, often changing considerably between customers. Fig. 1 shows two individual customer electricity load profiles, over a $24 \mathrm{~h}$ period for a random day. The differences between the customers are apparent with Customer 1 having two distinct peaks, one in the late morning and another in the evening time. Customer 2's profile on the other hand has a double peak in the late morning and no significant peaks in the afternoon or evening periods.

Residential smart meters have been installed in a number of countries around the world such as: Italy, Sweden, Netherlands, Canada and Northern Ireland [4]. In July 2009, the largest electricity supplier in the Republic of Jreland - Electric Ireland (formally Electricity Supply Board) ${ }_{\Lambda}$ commenced a smart metering trial for the domestic sector and small-to-medium enterprises. The trial consisted of metering approximately 4200 residential electricity customers at half hourly intervals as well as recording a detailed list of socio-economic, demographic and dwelling characteristics

0378-7788/\$ - see front matter (c) 2012 Published by Elsevier B.V. doi:10.1016/j.enbuild.2012.01.037 

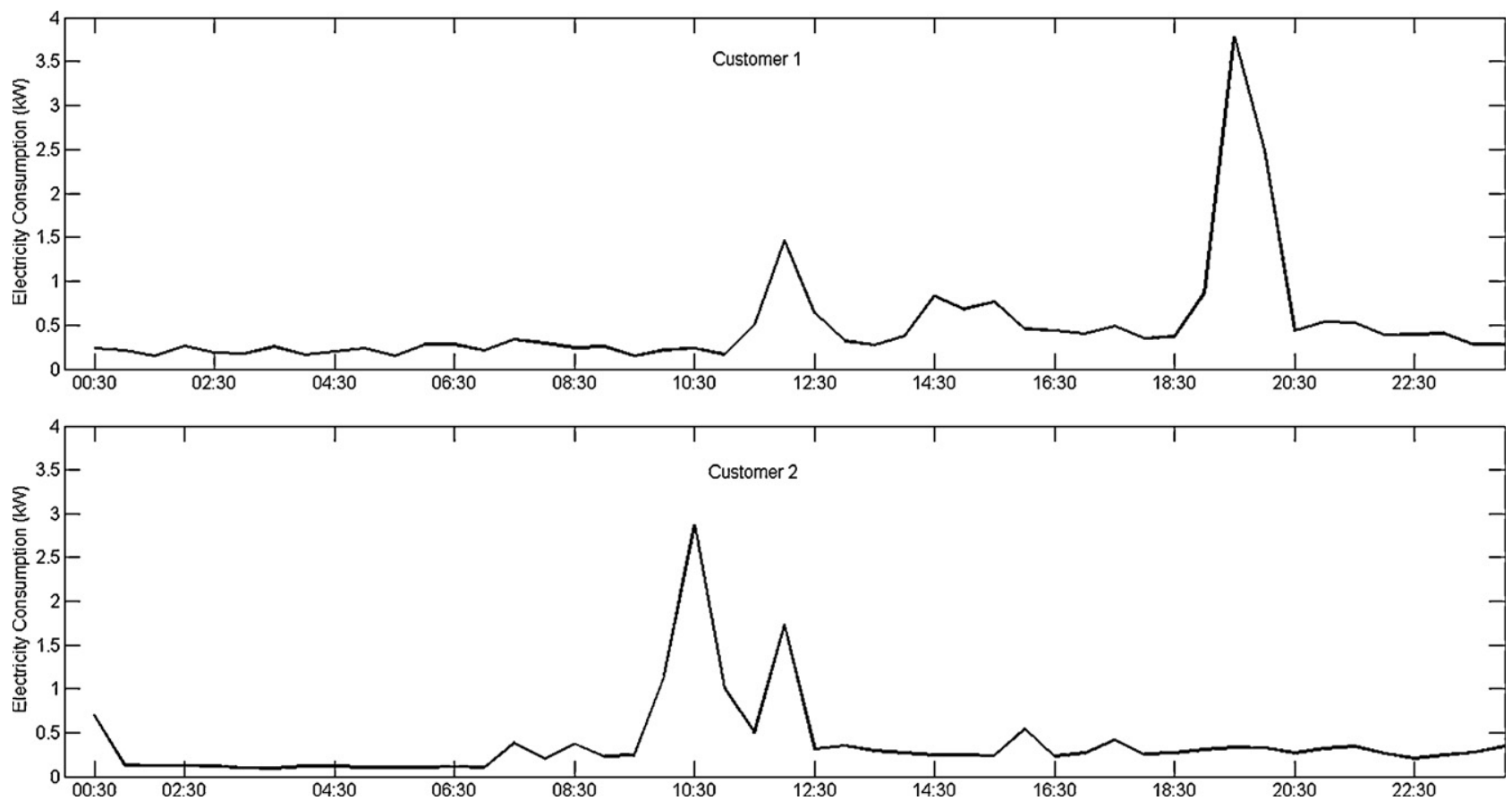

Fig. 1. Daily electricity load profile for an individual dwelling across a 24 h period.

for each household. The collection of such a detailed list of dwelling and occupant characteristics, combined with half hourly metering for 4200 individual customers offers a unique opportunity to investigate the drivers of electricity consumption patterns in the home. The dataset allows a detailed analysis of not only the affect of dwelling and occupant characteristics on total electricity demand but also on other load profile properties such as maximum demand, load factor and time of use (ToU) of maximum electricity demand.

The aim of this paper is to present results for dwelling and occupant characteristics that most significantly influence electricity consumption patterns in the home. As a result certain groups may be targeted where electricity savings and high renewable energy penetration can be achieved, thereby contributing towards meeting EU policy goals. Similarly, by determining electrical appliance characteristics that influence electricity consumption patterns at peak times will enable policy makers to identify measures to help reduce maximum demand.

\section{Literature}

There are various different approaches to modelling domestic electricity consumption, each with their individual strengths and weaknesses. The literature has been categorised below in terms of technique applied:

- Statistical/regression

- Engineering

- Neural network

Statistical/regression models can be considered to be both a "top-down" and a "bottom-up" method of modelling. Top-down approaches take data collected at an aggregate level such as national energy statistics, GDP and population figures to derive causal relationships between determinants and electricity consumption. Bottom-up models use data collected at an individual dwelling level to determine relationships between household characteristics and electricity use. Engineering and neural networks for the most part are considered to be a "bottom-up" modelling approach as they use data gathered at the dwelling level to infer relationships between electricity use and dwelling and occupant characteristics.

Statistical/regression models are particularly useful when a large dataset exists as they are based on real data and give a good understanding of electricity consumption patterns. However, they can be costly to implement and sometimes suffer from multi-collinearity between variables. O'Doherty et al. [5] used data from a National Survey of Housing Quality and applied a Papke-Wooldridge generalised linear model to infer a relationship between appliance ownership and electricity consumption. Their analysis showed explanatory variables that had a high significance for electricity consumption such as: dwelling characteristics; location, value and dwelling type as well as occupant characteristics; income, age, period of residency, social class and tenure type. Leahy and Lyons [6] applied an ordinary linear least squares regression using Irish Household Budget Survey data. Disposable income, household size, dwelling age and socio-economic group were amongst the variables that were shown to influence electricity consumption in the home. A variant of the statistical/regression approach is a Conditional Demand Model (CDA) first developed by Parti and Parti [7]. Monthly electricity bills over a yearly period were regressed against appliance ownership figures and demographic variables such as household income and number of occupants to disaggregate electricity demand into 16 different end-uses. This methodology showed the high significance of appliance ownership over electricity consumption patterns across a $24 \mathrm{~h}$ period.

Yohanis et al. [8] analysed patterns of electricity consumption in 27 representative dwellings in Northern Ireland. Electricity load profiles were characterised based on dwelling type, floor area, number of occupants, number of bedrooms, tenure, occupant age and household income. In particular, the authors found a significant relationship between domestic electricity consumption and floor area. Hart and de Dear [9] used regression to determine a relationship between external temperature and household electricity consumption in New South Wales, Australia. Their research concluded 
that there was a significant relationship between external temperature and electricity consumption and that this tended to be stronger during periods of cooler weather. Parker [10] also looked at the effect of external temperature on electricity consumption by applying linear regression. Fifteen minute data was collected from 204 residences in Central Florida, USA, looking at total electricity consumption, space heating/cooling and water heating. A significant relationship was also found between all electricity end-uses and external temperature. However, it is important to note that both preceding studies presented by Hart and de Dear and Parker were carried out in hot climates where electricity is commonly used to heat and cool homes, something which is not replicated in more temperate climates such as the United Kingdom and Ireland.

Engineering models use information such as appliance power ratings or end-use characteristics to build up a description of electricity consumption patterns from the "bottom-up". One of the major strengths associated with such models is that they are the only methodology that can model electricity consumption without any historical information on electricity use. However, engineering models can be complex to implement and need to be validated. Yao and Steemers [11] developed a dynamic software model to generate load profiles based on occupancy patterns, appliance ownership and ratings. The authors categorised electricity consumption determinants based on two categories: behavioural and physical, both of which are strongly related to dwelling occupancy patterns. Behavioural determinants relate to decisions made on a hourly/daily/weekly basis regarding use of particular appliances. Physical determinants relate to "fixed" variables that do not change often or at all with time such as dwelling size. Widen and Wackelgard [12] used time-use data (i.e. occupant's schedule of living activities) as well as appliance holdings, ratings and daylight distributions to produce electricity load profiles. Three sets of Swedish time-use data and energy measurements were used to model and validate results. The authors found it to be an effective way of generating individual load profiles. Shimoda et al. [13] modelled electricity consumption on an hourly basis for different dwelling and household characteristics in Osaka city, Japan. The authors showed that occupant's time-use, external temperature, appliance efficiencies and dwelling thermal characteristics all significantly influenced the electricity consumption pattern across the day. Capasso et al. [14] modelled electricity consumption patterns at a 15 min period, where various socioeconomic, demographic, psychological and behavioural characteristics of a homeowner as well as appliance characteristics were used to produce an electricity load profile. Homeowner's occupancy patterns as well as appliance ownership, usage and ratings contributed significantly to constructing the load profile shapes. Papadopoulos et al. [15] applied EnergyPlus simulation software to model two multifamily domestic buildings energy use to determine the optimum economic and environmental performance of space heating types in two Greek cities. The authors compared three types: oil fired boiler, heat pumps and electric radiators and gas fired boilers, with the latter outperforming the other two types significantly. However, the authors also concluded that under certain circumstances electrically driven heat pumps can rival gas fired space heating and favour renewable energy production in the home.

Neural networks use a mathematical model of biological networks to simulate electricity consumption in a dwelling. It is a variant of the engineering subgroup, modelling input determinant variables as a series of neurons. Each neuron can interact with others through a feedback mechanism. Historically they have been used to forecast electricity demand at a utility level, however, they have also been applied at a domestic level. Neural networks model a complex number of input parameters that affect electricity consumption in the home as well as the influence of each parameter on each other. Their self learning capabilities can result in an accurate means of modelling electricity consumption within the home. However, like CDA, neural networks can also suffer from multi-collinearity issues where high levels of appliance saturation exist. Aydinalp et al. [16] developed a neural network to model electricity consumption for domestic appliances, lighting and space cooling in the home. Aydinalp et al. [17] extended this work to develop neural network models for space and domestic hotwater heating. Aydinalp et al. [18] also carried out a comparison of neural network, conditional demand analysis and engineering approaches to modelling end-use energy consumption in the residential sector. Variables used in the neural network model that influenced electricity consumption were appliance ownership and usage, income, dwelling type and household composition.

Past literature has identified key variables that influence electricity consumption in the home [5-13,16,19-27]. Fig. 2 ranks the number of citations of each of these variables in this literature. The top four variables, dwelling type, household income, appliance holdings and number of occupants appear frequently in the literature. However, it is important to note that the frequent occurrence of certain variables may also be a consequence of the ease with which data was collected. For instance, data relating to the top four variables cited in Fig. 2 can be obtained from national census and household budget surveys with relative ease. Other variables such as floor area may be overlooked due to the difficulty with which this information is gathered, particularly for large sample sizes.

Dwelling and household characteristics used in the analysis were based on the ranking system shown in Fig. 2 and the information that was available from the smart metering survey. Yohanis et al. [8] showed that electricity consumption was highly correlated to number of bedrooms. For this reason and because reliable data on floor area was not available from the smart metering survey, number of bedrooms was used as a proxy instead. Santamouris et al. [28] found a significant relationship between income groups and domestic energy consumption. The information gathered on household income from the smart metering survey was found to be unreliable and therefore another means of determining this effect was sought. The Irish National Employment Survey 2008-2009 [29] showed a relationship between income and social class and therefore this variable was used as a proxy instead. The location of individual dwellings was not included in the analysis as the survey did not record this information. Dwelling age and tenure type were found to be highly correlated with $\mathrm{HoH}$ age and caused multi-collinearity between variables and therefore only $\mathrm{HoH}$ age was included for that reason. Similarly number of occupants was highly correlated with household composition. External temperature was not included as air conditioning is practically non-existent in the domestic sector in Ireland and electric space heating only constituted a very small proportion of the sample (less than $3 \%$ ). An efficiency variable was included to determine individual customer's intentions to reduce their overall electricity consumption which will be discussed later.

\section{Methodology}

The data set used in the analysis was taken from a population of 345,645 households. The population was divided into six groups based on total annual household electricity consumption to ensure an even spread of electricity consuming customers. An initial sample of 5574 was drawn on a randomised basis across all profiles. This was subsequently reduced to 5375 households by targeting certain groups to improve representivity of dwelling and socioeconomic variables within the sample size. A final sample size of 3941 households was used in the analysis, once large outliers 


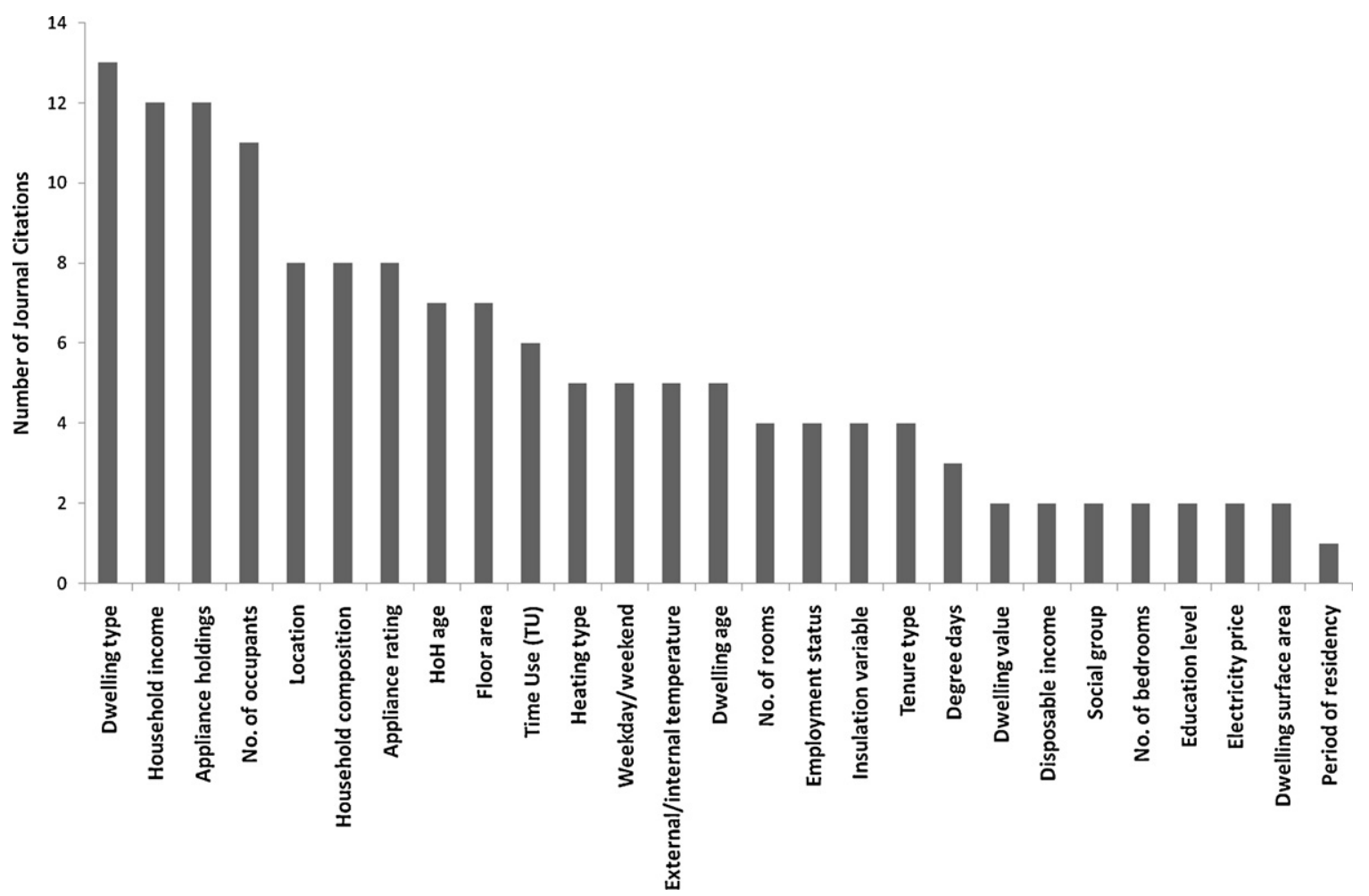

Fig. 2. Dwelling and occupant characteristics that influence domestic electricity consumption patterns.

and non-continuous data (a result of technology communication errors) were removed. Dwelling and occupant characteristics were collected by means of a phone interview.

Initially a six month period between 1st July 2009 and 31st December 2009 was used as a benchmark to ensure all smart meters, communication and IT systems were functioning satisfactorily. After this period, the customers were subjected to four different tariff structures and four different stimuli to investigate the impact on driving demand reduction over the calendar year for 2010. A control group of 1000 customers was unaffected by these measures over the yearly period. As this paper was primarily concerned with investigating dwelling and occupant characteristics that are most influential in affecting domestic electricity demand, the benchmark period of six months was used for the analysis due to its large sample size and independence from any tariff changes or stimuli.

This paper examines the effect of dwelling and occupant characteristics and household appliances on four dependent parameters: total electricity consumption, maximum demand, load factor and time of use (ToU) of maximum electricity consumption. The parameters were chosen so as to describe electricity consumption patterns in the home over a six month and $24 \mathrm{~h}$ period. The four electrical parameters are presented in Eqs. (1)-(4). E $E_{\mathrm{TOTAL}}$ is the total amount of electricity consumed over a six month period in $\mathrm{kWh}$ where $E_{i}$ is electrical demand in $\mathrm{kW}$ for each half hour period and $l$ is the total number of half-hourly periods over the six months.

$E_{\Lambda}{ }_{\text {TOTAL }}=\frac{1}{2} \sum_{i=1}^{l} E_{i}$

Eq. (2) describes mean daily maximum demand, $E_{\mathrm{MD}}$ over a six month period in $\mathrm{kW}$. $E_{\mathrm{MD}}$ refers to the largest value of electrical demand in a day, averaged over a six month period where $E_{i}$ is electrical demand in $\mathrm{kW}$ for each half hour period, $n$ is the total number of periods in a day and $m$ is the total number of days over the six month period.

$E_{\mathrm{MD}}=\frac{1}{m} \sum_{j=1}^{m} \max _{\lambda}\left\{E_{i}, 1 \leq i \leq n\right\}$

Daily load factor, $E_{\mathrm{LF}}$ is a ratio and is shown in Eq. (3). It is a measure of daily mean to daily maximum electrical demand and is a measure of the "peakyness" of a customer's load profile. Typically, larger load factors correspond to customers who consume electricity more evenly across the day where as a low load factor indicates small intervals of large electricity consumption. Eq. (3) describes daily load factor, $E_{\mathrm{LF}}$, where $E_{i}$ is electrical demand in $\mathrm{kW}$ over each half hour period, $n$ is the total number of periods in a day and $m$ is the total number of days over the six month period.

$E_{\mathrm{LF}}=\frac{1}{m} \sum_{j=1}^{m} \frac{(1 / n) \sum_{i=1}^{n} E_{i}}{\max \left\{E_{i}, 1 \leq i \leq n\right\}}$

A maximum ToU parameter, $E_{\mathrm{ToU}}$ over a six month period is defined by Eq. (4) where $E_{i}$ represents the maximum value of electricity consumption in a day and $j_{\max }$ corresponds to the time at which it occurs (where $1=00: 30$ and $48=00: 00$ ), $n$ is the total number of periods in a day and $m$ is the total number of days over the six month period. ToU indicates the time of day at which maximum electricity consumption occurs.

$E_{\mathrm{ToU}}=\operatorname{mode}\left\{j_{\max } \mid E_{j_{\max }}=\max \left\{E_{i}, 1+n(j-1) \leq i \leq n, 1 \leq j \leq m\right\}\right\}$

Multiple linear regression was applied to model the variation in electrical parameters presented above due its suitability in handling large amounts of qualitative data corresponding to occupant socio-economic variables, and also its extensive use in literature to model electricity demand profiles [5-7,19-22]. Two 
Table 1

Descriptive statistics for electrical parameters.

\begin{tabular}{|c|c|c|c|c|c|c|c|}
\hline Parameter & Mean & Median & $\begin{array}{l}\text { Standard } \\
\text { deviation }\end{array}$ & Maximum & Minimum & $\begin{array}{l}\text { Probability } \\
\text { distribution scale } \\
\text { parameter }(\eta)\end{array}$ & $\begin{array}{l}\text { Probability } \\
\text { distribution shape } \\
\text { parameter }(\beta)\end{array}$ \\
\hline Total electricity consumption ( $\left.E_{\mathrm{TOTAL}}\right)$ & $2261 \mathrm{kWh}$ & $2142 \mathrm{kWh}$ & $1108 \mathrm{kWh}$ & $10,065 \mathrm{kWh}$ & $99 \mathrm{kWh}$ & 2555 & 2.15 \\
\hline Maximum demand $\left(E_{\mathrm{MD}}\right)$ & $\hat{2} .50 \mathrm{~kW}$ & $2.49 \mathrm{~kW}$ & $1.01 \mathrm{~kW}$ & $7.36 \mathrm{~kW}$ & $0.07 \mathrm{~kW}$ & $\hat{2} .81$ & 2.65 \\
\hline Load factor $\left(E_{\mathrm{LF}}\right)$ & $23.43 \%$ & $22.53 \%$ & $6.33 \%$ & $82.00 \%$ & $8.13 \%$ & $-1.4873^{\mathrm{a}}$ & $0.1389^{a}$ \\
\hline $\operatorname{ToU}\left(E_{\mathrm{ToU}}\right)$ & 31.40 & 35.00 & 9.85 & $\mathrm{n} / \mathrm{a}$ & $\mathrm{n} / \mathrm{a}$ & $\hat{\mathrm{n}} / \mathrm{a}$ & $\mathrm{n} / \mathrm{a}$ \\
\hline
\end{tabular}

Weibull probability distribution function $f(T)=\beta / \eta(T / \eta)^{\beta-1} e^{-(T / \eta)^{\beta}}$ where $f(T) \geq 0, \quad T \geq 0, \quad \beta>0, \quad \eta>0$.

${ }^{a} \log -\log$ istic probability distribution function $f(T)=e^{z} /\left(\beta T\left(1+e^{z}\right)^{z}\right)$ where $z=\left(T^{\prime}-\eta\right) / \beta, \quad T^{\prime}=\ln (T), \quad 0<T<\infty, \quad-\infty<\eta<\infty, \quad 0<\beta<\infty$.

different models were developed: first looking at dwelling and occupant variables and secondly looking at individual appliances that influenced electricity consumption patterns in the home. The first model, dwelling and occupant characteristics (DOC), describes the variables that influence electricity consumption in the home such as $\mathrm{HoH}$ age and number of occupants and pedrooms, etc. These variables do not "consume" electricity but serve to influence occupants demand within the home and may help explain the underlining causes of different patterns of electricity use. The second model, electrical appliances (EA), looks directly at the individual appliances and describes the direct relationship between their ownership and use on electricity consumption patterns within the household. This model serves to give a better prediction of patterns of electricity use but does not explain underlining causes.

\section{Results and discussion}

Descriptive statistics such as mean, median and standard deviation values are presented for each electrical parameter in Table 1. Probability distribution functions are fitted to Eqs. (1)-(3), with scale and shape parameters also presented in the table.

A multiple linear regression was carried out using the following variables: dwelling type, number of bedrooms, head of household $(\mathrm{HoH})$ age, household composition, $\mathrm{HoH}$ social class, water heating type, cooking type and an efficiency indicator. A full listing of the independent variables used in the analysis are shown in Table 2, with base variable highlighted in bold italics where dummy categorical variables are used.

Other independent variables tested for significance included dwelling age, $\mathrm{HoH}$ employment status, tenure type, $\mathrm{HoH}$ education level and space heating type. These variables were omitted from the analysis since they either showed little or no significance over the tested parameters or showed a high degree of multi-collinearity with other independent variables. In particular, $\mathrm{HoH}$ age showed strong collinearity with dwelling age and tenure type with Pearson correlation coefficients exceeding $35 \%$ in both cases. This can be explained by younger HoH's having a higher percentage of mortgages and occupying newer dwellings. In comparison, a higher percentage of older HoH's have their mortgage paid off and live in older dwellings. HoH employment status and education level had little effect on the parameters and showed high collinearity to $\mathrm{HoH}$ social class with Pearson correlation coefficients exceeding $25 \%$. Space heating type (electric and non-electric) had no significance at all over the four parameters, due to the very low penetration of electric heating (less than 3\%) in Ireland.

Table 3 shows the results for the linear regression for the DOC model and each of the four dependent parameters with variables listed in Table 2 . The significance of variables on each parameter is shown by way of a $p$ value, indicating $90 \%, 95 \%$ and $99 \%$ significance levels.

Linear regression was carried out a second time for the EA model with the same four dependent parameters as before and fifteen common household appliances as explanatory variables. The results are presented in Table 4 alongside household appliance
Table 2

List of independent variables used in regression model

\begin{tabular}{|c|c|c|}
\hline Variable name & Variable explanation & $\begin{array}{l}\text { Sample } \\
\text { size }(N) \\
\end{array}$ \\
\hline Dwell_type_detach & $\begin{array}{l}\text { Dwelling is detached (includes } \\
\text { bungalows) }\end{array}$ & 2068 \\
\hline Dwell_type_semi_d & Dwelling is semi-detached & 1230 \\
\hline Dwell_type_terr & Dwelling is terraced & 569 \\
\hline Dwell_type_apt & Dwelling is apartment & 67 \\
\hline $\begin{array}{l}\text { No_bedrooms } \\
{ }^{1} \wedge^{-6}\end{array}$ & $\begin{array}{l}\text { Dwelling has one to six } \\
\text { bedrooms }\end{array}$ & 3941 \\
\hline HoH_age_18_35 & $\begin{array}{l}\text { Head of household age } \\
\text { between } 18 \text { and } 35\end{array}$ & 390 \\
\hline HoH_age_36_55 & $\begin{array}{l}\text { Head of household age } \\
\text { between } 36 \text { and } 55\end{array}$ & 1776 \\
\hline HoH_age_56plus & $\begin{array}{l}\text { Head of household age above } \\
55\end{array}$ & 1753 \\
\hline HH_comp_live_alone & $\begin{array}{l}\text { Household composition }{ }_{\wedge} \text { live } \\
\text { alone }\end{array}$ & 756 \\
\hline HH_comp_with_adults & $\begin{array}{l}\text { Household composition } \bar{\wedge} \text { live } \\
\text { with adults }\end{array}$ & 2064 \\
\hline ¿HH_comp_with_adults_and & $\begin{array}{l}1 \text { Hlloiludehiold composition }{ }_{-} \text {live } \\
\text { with adults and children }\end{array}$ & 1121 \\
\hline HoH_social_class_AB & $\begin{array}{l}\text { High and intermediate } \\
\text { managerial, administrative or } \\
\text { professional }\end{array}$ & 593 \\
\hline HH_social_class_C & $\begin{array}{l}\text { Supervisory and clerical and } \\
\text { junior managerial, skilled } \\
\text { manual workers }\end{array}$ & 1697 \\
\hline HH_social_class_DE & $\begin{array}{l}\text { Semi-skilled and unskilled } \\
\text { manual workers, state } \\
\text { pensioners, unemployed }\end{array}$ & 1505 \\
\hline HH_social_class_F & Farmers & 107 \\
\hline Water_heat_non_electric & $\begin{array}{l}\text { Water is heated by other (oil, } \\
\text { gas, solid fuel) }\end{array}$ & 3144 \\
\hline Water_heat_electric & Water is heated by electricity & 771 \\
\hline Cooking_type_non_electric & $\begin{array}{l}\text { Cooking is mostly done by } \\
\text { non-electric means (oil, gas, } \\
\text { solid fuel) }\end{array}$ & 1192 \\
\hline Cooking_type_electric & $\begin{array}{l}\text { Cooking is mostly done by } \\
\text { electricity }\end{array}$ & 2749 \\
\hline Efficiency_less_10 & $\begin{array}{l}\text { HoH who believe they can cut } \\
\text { electricity consumption by } \\
10 \%\end{array}$ & 1950 \\
\hline Efficiency_betw_10_20 & $\begin{array}{l}\text { HoH who believe they can cut } \\
\text { electricity consumption by } \\
\text { between } 10 \% \text { \& } 20 \%\end{array}$ & 916 \\
\hline Efficiency_betw_20_30 & $\begin{array}{l}\text { HoH who believe they can cut } \\
\text { electricity consumption by } \\
\text { between } 20 \% \text { \& } 30 \%\end{array}$ & 345 \\
\hline Efficiency_more_30 & $\begin{array}{l}\text { HoH who believe they can cut } \\
\text { electricity consumption by } \\
\text { more than } 30 \%\end{array}$ & 123 \\
\hline
\end{tabular}


Table 3

Regression results for dwelling and occupant characteristics model (DOC).

\begin{tabular}{|c|c|c|c|c|c|c|c|c|}
\hline & \multicolumn{2}{|c|}{ Total_elec_consumption } & \multicolumn{2}{|c|}{ Maximum_demand } & \multicolumn{2}{|c|}{ Load_factor } & \multicolumn{2}{|l|}{ ToU } \\
\hline & Coef. & Std. error & Coef. & Std. error & Coef. & Std. error & Coef. & Std. error \\
\hline (Constant) & 18.6055 & 101.633 & $0.6388^{* * *}$ & 0.092 & $0.2169^{* * *}$ & 0.0068 & $29.4659^{* * *}$ & 1.0786 \\
\hline Dwell_type_semi_d & $-175.6725^{* * *}$ & 34.1701 & $-0.0766^{* *}$ & 0.0309 & $-0.0082^{* * *}$ & 0.0023 & -0.414 & 0.3626 \\
\hline Dwell_type_terr & $\hat{-} 147.045^{* * * *}$ & 45.9229 & $\hat{\wedge}_{-0.0583}$ & 0.0416 & $-0.0114^{* * *}$ & 0.0031 & $-1.2872^{* *}$ & 0.4874 \\
\hline Dwell_type_apt & $\hat{-} 245.5571^{* *}$ & 119.4231 & $-0.2963^{* *}$ & 0.1081 & 0.0084 & 0.008 & 0.1958 & 1.2674 \\
\hline No_bedrooms & $349.036^{* * *}$ & 19.9182 & ${ }^{\wedge} 0.2365^{* * *}$ & 0.018 & $0.0089^{* * *}$ & 0.0013 & $0.6785^{* * *}$ & 0.2114 \\
\hline HoH_age_36_55 & $282.8721^{* * *}$ & 51.7462 & 0.0722 & 0.0468 & $0.0171^{* * *}$ & 0.0034 & $-0.9431^{*}$ & 0.5492 \\
\hline HoH_age_56_plus & $212.0358^{* * *}$ & 57.7676 & $-0.1515^{* * *}$ & 0.0523 & $0.0318^{* * *}$ & 0.0038 & $-2.0417^{* * *}$ & 0.6131 \\
\hline HH_comp_with_adults & $730.9512^{* * *}$ & 40.7046 & ${ }^{\wedge} 0.7036^{* * *}$ & 0.0368 & -0.0022 & 0.0027 & $\wedge^{\prime} 1.2854^{* * *}$ & 0.432 \\
\hline $\begin{array}{l}\text { HH_comp_with_adults_ } \\
\text { and_children }\end{array}$ & $1083.688^{* * *}$ & 50.2313 & $0.9853^{* * *}$ & 0.0455 & ${ }^{\wedge} 0.0043$ & 0.0033 & $2.0295^{* * *}$ & 0.5331 \\
\hline HoH_social_class_C & $-73.6939^{*}$ & 44.1127 & 0.0407 & 0.0399 & $-0.0134^{* * *}$ & 0.0029 & $1.2344^{* *}$ & 0.4682 \\
\hline HoH_social_class_DE & $\hat{-132.952^{* *}}$ & 48.522 & -0.0146 & 0.0439 & ${ }^{\wedge}-0.0155^{* * *}$ & 0.0032 & 0.8489 & 0.515 \\
\hline HoH_social_class_F & $\hat{-} 370.2021^{* * *}$ & 98.0024 & $-0.2591^{* * *}$ & 0.0887 & -0.0016 & 0.0065 & $-2.8708^{* *}$ & 1.0401 \\
\hline Water_heat_electric & ${ }^{\wedge} 148.9229^{* * *}$ & 29.5042 & $\wedge_{0.2379^{* * *}}$ & 0.0267 & $-0.0077^{* * *}$ & 0.002 & $-1.3368^{* * *}$ & 0.3131 \\
\hline Cooking_type_electric & $185.6567^{* * *}$ & 32.2118 & $0.3896^{* * *}$ & 0.0292 & $\hat{-} 0.0241^{* * *}$ & 0.0021 & 0.1381 & 0.3419 \\
\hline Efficiency_betw_10_20 & $142.7689^{* * *}$ & 37.6209 & $0.1139^{* * *}$ & 0.0341 & ${ }^{\wedge} 0.0015$ & 0.0025 & -0.4104 & 0.3993 \\
\hline Efficiency_betw_20_30 & $188.2471^{* * *}$ & 54.1685 & $0.1638^{* * *}$ & 0.049 & 0.0021 & 0.0036 & ^ 0.2999 & 0.5749 \\
\hline Efficiency_more_30 & $274.1978^{* * *}$ & 85.5507 & $0.1476^{*}$ & 0.0774 & 0.0089 & 0.0057 & -0.57 & 0.908 \\
\hline
\end{tabular}

Base variables: Dwelling_type_detach, HoH_age_18_35, HH_comp_live_alone, HoH_social_class_AB, Water_heat_non_electric, Cooking_type_non_electric, Efficiency_less_10

$$
\text { *** } \begin{aligned}
& p<0.1 . \\
& p<0.05 . \\
& p<0.01
\end{aligned}
$$

penetration levels. The base variable chosen for the analysis was washing machine due to its high penetration level of $98.3 \%$ within the survey.

\subsection{Total electricity consumption}

Total electricity consumption was regressed against dwelling and occupant variables described in Table 2 and a coefficient of determination of $32 \%$ was recorded for the DOC model. All dwelling types had a negative effect on total electricity consumption when compared to the base variable detached dwelling, which included bungalows. As expected, apartments had significantly lower total electricity consumption than all other dwelling types, a result of their smaller size and fewer number of occupants. For each additional bedroom, total electricity consumption on average increased $349 \mathrm{kWh}$ over the six month period. On a per capita basis, total electricity consumption for the residential sector accounted for $948 \mathrm{~kW}$ h over the six month period. This suggests that planning laws in favour of smaller dwellings or a property tax to encourage older lone HoH's (whose children have vacated the family home) to downsize, would reduce overall electricity demand for the sector.

Electricity consumption for younger HoH's was significantly lower when compared to the other two age categories, 36-55 and 56 plus. This could be attributed to middle aged HoH's having more children living at home (thus having a higher number of occupants) and increased occupancy patterns (i.e. dwelling occupants at home for longer periods of the day). This is also apparent when looking at household composition: adults living with children consume considerably more electricity than those living alone or with other adults. $\mathrm{HoH}$ social class had a negative effect on total electricity consumption when compared against the base category $A B$, representing Higher Professionals. Social class was used as a proxy in the absence of reliable data on household income. This suggests that Higher Professionals are inclined to consume more electricity than Lower Professionals with the former tending to live in larger dwellings and have a greater number of electrical appliances, suggesting a possible income effect.

\begin{tabular}{|c|c|c|c|c|c|c|c|c|c|}
\hline & \multirow{2}{*}{$\begin{array}{l}\text { Household appliance } \\
\text { penetration }\end{array}$} & \multicolumn{2}{|c|}{ Total_elec_consumption } & \multicolumn{2}{|c|}{ Maximum_demand } & \multicolumn{2}{|l|}{ Load_factor } & \multicolumn{2}{|l|}{ ToU } \\
\hline & & Coef. & Std. exrror & Coef. & Std. error & Coef. & Std. error & Coef. & Std. error \\
\hline (Constant) & & $656.9107^{* * *}$ & 51.3526 & $0.8771^{* * *}$ & 0.0472 & $0.2444^{* * *}$ & 0.0035 & $29.8274^{* * *}$ & 0.5578 \\
\hline Tumble dryer & $68 \%$ & $375.3768^{* * *}$ & 33.5586 & $0.3951^{* * *}$ & 0.0309 & $\bar{\Lambda}^{-0.0045^{*}}$ & 0.0023 & -0.1742 & 0.3645 \\
\hline Dishwasher & $67 \%$ & $406.0503^{* * *}$ & 33.7939 & $0.2894^{* * *}$ & 0.0311 & ${ }^{\wedge} 0.0128^{* * *}$ & 0.0023 & $1.4145^{* * *}$ & 0.3671 \\
\hline Shower (instant) & $69 \%$ & 44.0911 & 32.8842 & $0.2557^{* * *}$ & 0.0302 & $\bar{\Lambda}^{-0.0189^{* * *}}$ & 0.0022 & $-1.1625^{* * *}$ & 0.3572 \\
\hline Shower (pumped) & $29 \%$ & 34.5628 & 33.0484 & -0.0159 & 0.0304 & ${ }^{\wedge} 0.0025$ & 0.0022 & -0.2293 & 0.359 \\
\hline Electrical cooker & $76 \%$ & $182.6508^{* * *}$ & 34.2263 & $\wedge_{0.3758^{* * *}}$ & 0.0315 & $-0.0241^{* * *}$ & 0.0023 & ${ }^{\wedge} 0.5208$ & 0.3718 \\
\hline Heater (plug in convective) & $30 \%$ & $56.5369^{*}$ & 31.4838 & -0.0339 & 0.029 & ${ }^{\wedge} 0.008^{* * *}$ & 0.0021 & $-1.1678^{* * *}$ & 0.342 \\
\hline Freezer (stand alone) & $50 \%$ & $198.131^{* * *}$ & 29.6764 & $\wedge_{0.0775^{* * *}}$ & 0.0273 & $0.0129^{* * *}$ & 0.002 & $\wedge_{0.0618}$ & 0.3224 \\
\hline Water pump & $20 \%$ & $208.1565^{* * *}$ & 36.7427 & $0.0902^{* *}$ & 0.0338 & $0.0063^{* *}$ & 0.0025 & $0.7612^{*}$ & 0.3991 \\
\hline Immersion & $77 \%$ & $73.4666^{* *}$ & 34.6355 & $0.1701^{* * *}$ & 0.0319 & $-0.0068^{* * *}$ & 0.0023 & -0.4635 & 0.3762 \\
\hline No. $\operatorname{TV}_{\wedge}<21$ in. & $66 \%$ & $100.8994^{* * *}$ & 15.8887 & $0.1059^{* * *}$ & 0.0146 & $\hat{\Lambda}-0.0017$ & 0.0011 & $0.434^{* *}$ & 0.1726 \\
\hline No. $T V>21$ in. & $84 \%$ & $197.2184^{* * *}$ & 18.4409 & $0.1393^{* * *}$ & 0.017 & ${ }^{\wedge} 0.0026^{* *}$ & 0.0012 & $0.5456^{* *}$ & 0.2003 \\
\hline No. computer (desktop) & $48 \%$ & $287.3278^{* * *}$ & 26.4866 & $0.1626^{* * *}$ & 0.0244 & $0.0095^{* * *}$ & 0.0018 & $0.6874^{* *}$ & 0.2877 \\
\hline No. computer (laptop) & $54 \%$ & $135.1009^{* * *}$ & 19.7789 & $0.0978^{* * *}$ & 0.0182 & $0.0042^{* * *}$ & 0.0013 & 0.2103 & 0.2149 \\
\hline No. game consoles & $33 \%$ & $193.1296^{* * *}$ & 20.7689 & $0.1953^{* * *}$ & 0.0191 & 0.0017 & 0.0014 & 0.2495 & 0.2256 \\
\hline
\end{tabular}

Table 4

Regression results for electrical appliances model (EA).

Base variable: washing machine.

$$
{ }^{* *} \quad p<0.1 \text {. } \begin{aligned}
& { }^{* * *} \\
& p<0.05 .
\end{aligned}
$$


An indicator variable was also used to measure potential household electricity savings by asking those surveyed to quantify how much they believed they could cut their electricity consumption by changing their behaviour. The variable showed strong positive correlation with increasing electricity savings (i.e. respondents with higher electricity consumption believed they could make greater electricity savings than those who consumed less). This suggests that larger electricity consumers are wasteful (i.e. leave lights on in unoccupied rooms) and hence believe they can cut back on their electricity use. In contrast, those who consume less may believe that they are efficient in their use of electricity and cannot make further substantial cuts.

Table 4 shows regression results for the EA model, where a coefficient of determination of $32 \%$ was recorded. Tumble dryers, dishwashers, cookers, freezers, water pumps (used in low water pressure residential areas) and brown goods (televisions, computers, game consoles) were all significant at the 99\% level. Showers showed no significance at all and immersions were only significant at the $90 \%$ level resulting in the underestimation of electricity used for water heating in the home. It is also important to note that the analysis above is independent of lighting, which is a significant contributor to electricity consumption. Lighting demand could not be distinguished from the survey as the number of fittings was not recorded. Similarly, electrical appliance refrigerator was not recorded as part of the survey. As nearly all households will have some degree of lighting and refrigeration, this led to the over estimation of regression coefficients for other appliances such as tumble dryers, dishwashers and brown goods in Table 4.

\subsection{Maximum demand}

Maximum electricity demand was regressed against the variables listed in Table 3 and a coefficient of determination of 33\% was recorded for the DOC model. Maximum demand was significantly influenced by semi-detached and apartment dwellings at the 95\% level as shown in Table 3. When compared against the base variable (detached dwelling) each had a negative influence on maximum demand, particularly apartments. Number of bedrooms was significant at the $99 \%$ level and serves to increase maximum demand by $0.23 \mathrm{~kW}$ for every additional bedroom within a dwelling. Similarly, household composition significantly influenced maximum demand, with adults and children consuming nearly an extra kilowatt compared to the base variable (adult living alone). Apartment dwellings tend to be smaller in size, have fewer occupants and have a smaller stock of appliances than other dwelling types, all of which are drivers of maximum demand. As expected, homes with electric water heating and cooking also had higher maximum demands compared to those that use other methods to heat water and to cook.

The EA model recorded a coefficient of determination of 33\%. Almost all household appliances showed significant influence on maximum demand at the 99\% level. Pumped showers and plug in convective heaters were the only appliances not to show any significance at all, possibly due to their respective low power rating and off peak use. The three largest contributors to maximum electricity demand were tumble dryers, dishwashers and electric cookers which all have significant heating components in their operation. Instant electric showers and immersion appliances, both used for heating water were the next largest contributors.

Electricity generated at peak times such as early morning and evening times is far less efficient than electricity generated at other times of day. This is a direct result of running expensive peaking generation plant such as open cycle gas turbines to respond to quick changes in system demand, which are less efficient than other types of generation. Shifting demand away from peak times will result in a more efficient electricity system and as a consequence reduce greenhouse gas emissions for the sector. In particular, tumble dryers and dishwashers offer the best opportunity for shifting demand away from peak time use compared to electric cookers as they are less dependent on the timing of high priority household routines such as cooking. The introduction of time of use tariffs for the residential sector, so that electricity consumed at peak times reflects the true cost of generation, may encourage homeowners to shift non-essential appliance use to off peak times when electricity is cheaper.

\subsection{Load factor}

A significantly lower coefficient of determination, 9\%, was recorded for load factor in the DOC model compared to the previous two parameters. Load factor changes only slightly between customers as indicated by the low standard deviation for the parameter (6\%) shown in Table 1. However, the parameter is useful for determining the load profile shape of individual customers. A low load factor indicates customers whose electricity consumption pattern is high for short periods of time whereas a higher load factor indicates a more constant use of electricity across the day.

Semi-detached and terraced dwellings had a significant impact on load factor compared to the base variable (detached dwelling). Larger dwellings such as detached and semi-detached homes had a positive effect on load factor. For each additional bedroom, load factor on average increased by $1 \%$. HoH age also strongly influenced load factor in a positive manner with younger $\mathrm{HoH}$ groups having slightly lower load factors representing a more "peaky" load across the day. In contrast, older HoH groups have a larger load factor, indicating a smoother electricity consumption pattern across the day. This is most likely due to older HoH's living in larger dwellings, having more number of occupants and possibly more active in the home during the day. This was also shown by Richardson et al. [30] where home activity (i.e. switching on an electrical appliance) increases with number of occupants. Water heating and cooking type influenced load factor in a negative manner and therefore households that use electricty to heat water and cook will therefore tend to have lower load factors.

The EA model also recorded a coefficient of determination of $9 \%$ for load factor. Most household appliances were significant at the 99\% level except for tumble dryers, electric showers (pumped), water pumps, televisions and game consoles. When compared against the base variable washing machine, appliances with negaitive coefficients decrease load factor and corespond with high power devices that are not used continuously for long periods of time. In particular, electric showers (instant), cookers and immersions, which are all significant at the $99 \%$ level, tended to decrease load factor due to their high power requirements and result in a more "peaky" domestic load profile. Dishwashers and stand alone freezers on the other hand had a significant positive effect on load factor as they are switched on for longer periods of time.

\subsection{Time of kse (ToU)}

A poor coefficient of determination of $2.6 \%$ was recorded for $\mathrm{ToU}$ in the DOC model. However, the results may be somewhat distorted due to the bi-modal distribution of the regression residuals. Nevertheless, ToU showed high significance for household composition and $\mathrm{HoH}$ age. For $\mathrm{HoH}$ age, the older the head of the household the more negative the influence on the parameter indicating earlier use of maximum electricity consumption during the evening. Household composition had a positive effect on ToU with adults and children tending to use maximum electricity later in the evening compared to occupants living alone. Younger and middle aged groups correspond to households with young families and 
therefore tend to have a greater number of occupants. These groups are inclined to use maximum electricity later in the evening, most likely a result of increased number of active occupants later in the evening. Households with older HoH's tend to have fewer number of occupants, as children may have vacated the home and are also closer to retirement age and hence tend to be active earlier in the evening possibly due to lighter work commitments or retirement. Hence these groups are more likely to use maximum electricity earlier in the evening.

The EA model also recorded a poor coefficient of determination of $2.6 \%$ for ToU parameter. Appliances that showed a significance of $95 \%$ or higher were dishwasher, electric shower (instant), plug in convective heaters, televisions and computer desktops. Seebach et al. [31] ranked appliances in terms of their flexibility to shift demand away from peak time use. The suitability depended upon the following four characteristics: high load requirement, availability of appliance (i.e. an appliance use), appliance run time and convenience to the consumer. Dishwashers and electric water heaters ranked high when considering all four characteristics together. Based on the results from Table 4 it is possible to calculate the contribution of individual appliances to peak time electricity use based on ownership. The results from the last census carried out in 2006 showed that there were 1,462,296 private households in Ireland [32]. According to the survey, dishwasher penetration in Irish homes was $67 \%$ as shown in Table 4 . If $10 \%$ of households were to shift dishwasher use away from peak times a potential saving of $29 \mathrm{MW}$ of electricity generation capacity could be achieved.

\section{Conclusion}

Results are presented linking dwelling and occupant socioeconomic variables and electrical parameters: total electricity consumption, maximum demand, load factor and ToU for maximum electricity demand. Dwelling number of bedrooms, which was used as a proxy for dwelling size, was found to strongly influence total electricity consumption. Apartment dwellings, which are proportionally smaller and have less occupants and appliances, consumed the least electricity when compared to other dwelling types. HoH age group 36-55 were found to be the largest consumers of electricity, probably due to the prevalence of children living at home amongst this age group. Household social class was significant with Higher Professionals consuming more electricity than middle or lower classes, reflecting a possible income effect. Dwellings that used electricity for water heating and cooking also used a larger amount of electricity as would be expected. An efficiency variable also indicated the potential for reducing household electricity demand which showed significant positive correlation with the parameter, possibly indicating that larger electricity consumers are more wasteful of electricity than those whom consumed less. Appliances that consumed the most electricity were tumble dryers and dishwashers. Policy recommendations that could achieve a reduction in electricity consumption for the sector: planning laws to favour smaller dwellings and a property tax to encourage downsizing of older HoH's when their children have vacated the home.

Household composition, number of bedrooms, water heating and cooking type were the most significant variables to influence maximum electricity demand. It was also shown that the majority of common household electrical appliances included in the survey influenced maximum demand. However, three appliances in particular: tumble dryer, dishwasher and electric cooker, contributed significantly more than the base variable washing machine. The introduction of time of use tariffs should discourage the use of non high priority household tasks such as clothes and dish washing at peak times. Load factor was influenced by independent variables dwelling type and number of bedrooms. $\mathrm{HoH}$ age was also significant, with younger HoH's having smaller load factors representing a more "peaky" load profile shape. Water heating and cooking by electricity had the effect of lowering the overall load factor as these appliances tend to consume large amounts of electricity for relatively short periods of time. This was also apparent from the EA model where the three most significant appliances to reduce load factor were: electric shower (instant), cooker and immersion.

Time of use of maximum electricity demand was influenced more so by occupant rather than dwelling characteristics as one would expect. Older head of households are more likely to use maximum electricity consumption earlier in the day. This was also reflected in the household composition variable where adults and children, which correspond with younger HoH's, tending to use maximum electricity demand later in the day. Appliances that influenced ToU were dishwashers, electric showers, plug in convective heaters, televisions and computer desktops. The appliance that showed the greatest potential for shifting demand away from peak time use was the dishwasher due to its high power requirement and frequent use. It was calculated that by shifting $10 \%$ of installed dishwasher demand away from peak times, could result in a saving of $29 \mathrm{MW}$ of peak time electricity generation capacity. This suggests the potential for the introduction of time of use tariffs and/or smart appliances for the sector.

\section{Acknowledgement}

Dublin Institute of Technology would like to acknowledge the support of Electric Ireland for access to the dataset.

\section{References}

[1] Environment Protection Agency, Jreland's Greenhouse Gas Emissions in 2009, 2010.

[2] Department of Communications Energy and Natural Resources, The National Energy Efficiency Action Plan 2009-2020, 2009.

[3] Department of Communications Energy and Natural Resources, The National Renewable Energy Action Plan 2009-2020, 2009.

[4] Leonardo Energy, Smart Metering, 2006 (accessed 06.04.11) http://www. leonardo-energy.org/drupal/node/769.

[5] J. O’Doherty, S. Lyons, R. Tol, Energy-using appliances and energy-saving features: determinants of ownership in Ireland, Applied Energy 85 (7) (2008) 650-66̂े.

[6] E. Leahy, S. Lyons, Energy use and appliance ownership in Jreland, ESRI, Working Paper No. 277, 2009.

[7] M. Parti, C. Parti, The total and appliance specific conditional demand for electricity in the household sector, Bell Journal of Economics 11 (1) (1980) 309324.

[8] Y.G. Yohanis, J.D. Mondol, A. Wright, B. Norton, Real-life energy use in the UK: how occupancy and dwelling characteristics affect domestic electricity use, Energy and Buildings 40 (6) (2008) 1053-1059.

[9] HartF M., R. de Dear, Weather sensitivity in household appliance energy enduse, Energy and Buildings 36 (2) (2004) 161-174.

[10] D.S. Parker, Research highlights from a large scale residential monitoring study in a hot climate, Energy and Buildings 35 (9) (2003) 863-876.

[11] R. Yao, K. Steemers, A method of formulating energy load profile for domestic buildings in the UK, Energy and Buildings 37 (6) (2005) 663-671.

[12] J. Widen, E. Wackelgard, A high-resolution stochastic model of domestic activity patterns and electricity demand, Applied Energy 87 (2010) 1880-1892.

[13] Y. Shimoda, T. Fujii, T. Morikawa, M. Mizuno, Residential end-use energy simulation at city scale, Building and Environment 39 (8) (2004) 959-967.

[14] A. Capasso, W. Grattieri, R. Lamedica, A. Prudenzi, A bottom-up approach to residential load modelling, IEEE Transactions on Power Systems 9 (May (2)) (1994).

[15] A.M. Papadopoulos, S. Oxizidis, G. Papandritsas, Energy, economic and environmental performance of heating systems in Greek buildings, Energy and Buildings 40 (2008) 224-230.

[16] M. Aydinalp, V. Ugursal, A. Fung, Modeling of appliance, lighting, and spacecooling energy consumption in the residential sector using neural networks, Applied Energy 71 (2002) 87-110.

[17] M. Aydinalp, V. Ismet Ugursal, et al., Modelling of the space and domestic hot water heating energy-consumption in the residential sector using neural networks, Applied Energy 79 (2) (2004) 159-178.

[18] M. Aydinalp-Koksal, V.I. Ugursal, Comparison of neural network, conditional demand analysis, and engineering approaches for modeling end-use energy consumption in the residential sector, Applied Energy 85 (4) (2008) 271-296. 
[19] R. Bartels, D.G. Fiebig, Integrating direct metering and conditional demand analysis, Energy Journal 11 (4) (1990).

[20] B.M. Larsen, R. Nesbakken, Household electricity end-use consumption: results from econometric and engineering models, Energy Economics 26 (2) (2004) 179-200.

[21] S. Pachauri, An analysis of cross-sectional variations in total household energy requirements in India using micro survey data, Energy Policy 32 (2004) 1723-1735.

[22] M. Lenzen, M. Wier, C. Cohen, H. Hayami, S. Pachauri, R. Schaeffer, A comparative multivariate analysis of household energy requirements in Australia, Brazil, Denmark, India and Japan, Energy (2006) 181-207.

[23] S. Firth, K. Lomas, A. Wright, R. Wall, Identifying trends in the use of domestic appliances from household electricity consumption measurements, Energy and Buildings 40 (5) (2008) 926-936.

[24] A. Cagni, E. Carpaneto, G. Chicco, R. Napoli, Characterisation of the aggregated load patterns for extra-urban residential customer groups, in: JEEE Melecon 2004, May 12-15, Dubrovnik, Croatia, 2004.

[25] J. Widén, E. Wackelgard, A high-resolution stochastic model of domestic activity patterns and electricity demand, Applied Energy 87 (2010) 18801892.
[26] A. Entrop, G. Brouwers, H.A. Reinders, Evaluation of energy performance indicators and financial aspects of energy saving techniques in residential real estate, Energy and Buildings 42 (2010) 618-629.

[27] K. Genjo, S. Tanabe, S. Matsumoto, K. Hasegawa, H. Yoshino, Relationship between possession of electric appliances and electricity for lighting and others in Japanese households, Energy and Buildings 37 (2005) 259-272.

[28] M. Santamouris, K. Kapsis, D. Korres, I. Livada, C. Parlou, M.N. Assimakopoulos, On the relation between the energy and social characteristics of the residential sector, Energy and Buildings 39 (2007) 893-905.

[29] Central Statistics Office, National Employment Survey 2008 and 2009, 2011.

[30] I. Richardson, M. Thompson, D. Infield, A high-resolution domestic building occupancy model for energy demand simulations, Energy and Buildings 40 (2008) 1560-1566.

[31] D. Seebach, C. Timpe, D. Bauknecht, Costs and Benefits of Smart Appliances in Europe, 2009, D 7.2 of WP 7 from Smart-A Project. Table 4.

[32] Central Statistics Office, Number of Private Households and Persons in Private Households in Each Province, County and City - 2006, 2009 (accessed 17.05.11) http://www.cso.ie/quicktables/GetQuickTables.aspx?FileName=CNA33.asp\& TableName $=$ Number + of + private + households + and + persons + in + private + households+in+each+Province+,+County+and+City\&StatisticalProduct=DB_CN
691

692

694

695

696
697 